\title{
Effect of Heteroatom and Functionality Substitution on the Oxidation Potential of Cyclic Nitroxide Radicals: Role of Electrostatics in Electrochemistry
}

\author{
Kai Zhang, ${ }^{a}$ Benjamin B. Noble, ${ }^{\mathrm{b}}$ Adam C. Mater, ${ }^{\mathrm{b}}$ Michael J. Monteiro ${ }^{\mathrm{a}}$ Michelle L. Coote, ${ }^{\mathrm{b} *}$ and Zhongfan Jia ${ }^{\mathrm{a} *}$
}

The oxidation potential of a test set of 20 nitroxide radicals, including a number of novel compounds, has been studied experimentally in acetonitrile and correlated with theoretical calculations. It was found that both Hammett constants $\left(\sigma_{p}\right)$ of the substituents on the nitroxide radicals and hyperfine splitting constants of the respective nitrogen atoms $\left(\alpha_{N}\right)$ were well correlated to their experimental oxidation potentials. Theoretical calculations, carried out at the $\mathrm{G} 3(\mathrm{MP} 2, \mathrm{CC})(+) / / \mathrm{M} 06-2 \mathrm{X} / 6-31+\mathrm{G}(\mathrm{d}, \mathrm{p})$ level of theory with PCM solvation corrections, were shown to reproduce experiment to within a mean absolute deviation of $33 \mathrm{mV}$, with a maximum deviation of $64 \mathrm{mV}$. The oxidation potentials of the nitroxides examined varied over $400 \mathrm{mV}$, depending on ring size and substitution. This considerable variation can be rationalised by the ability of various substituents to electrostatically stabilize the oxidised oxoammonium cation. Importantly, this can be quantified by a simple predictive relationship involving the distance scaled dipole and quadrupole moments of the analogous cyclohexyl ring. This highlights the often-overlooked role of through-space electrostatic substituent effects, even in formally neutral compounds.

\section{Introduction}

Cyclic nitroxides, epitomised by TEMPO $(2,2,6,6-$ teramethylpiperidinyl-1-oxy) and its derivatives, are an important class of free-radicals that possess a long shelf life. The persistent nature of these nitroxides originates from: (1) electron delocalization along the $\mathrm{N}-\mathrm{O}$ bond and (2) the stabilization against combination and disproportionation by the four $\alpha$-methyl groups adjacent to the $\mathrm{N}-\mathrm{O}$ centre. Nitroxides have many applications, including as spin probes and spin labels, ${ }^{1,} 2$ superoxide dismutase mimics, ${ }^{3,4}$ antioxidants ${ }^{5-7}$ and control agents in 'living' radical polymerization. ${ }^{8,9}$ Early work, as summarised by Rozantsev, ${ }^{10}$ focussed on the comprehensive synthesis of functional nitroxides, including TEMPO, pyrrolidine (PROXYL) and pyrroline radicals as well as various derivatives, and their applications in biological systems. In recent years, there has been a resurgence in nitroxide synthesis because of their importance as oxidation catalysts, ${ }^{11-15}$ in radical coupling reactions ${ }^{16-19}$ and particularly in organic energy storage materials. ${ }^{20-24}$

In addition to their inherent stability against dimerization and disproportionation, the unpaired electron on nitroxide radicals imparts key characteristics of electron-spin and underpins their ability to undergo reversible redox reactions. In principle, any parameter that changes the electron distribution along the $\mathrm{N}-\mathrm{O}$ bond of a nitroxide will change its physical and chemical properties; including the electron paramagnetic resonance (EPR) spectrum and its behaviour in redox reactions. One of the key parameters of nitroxides that is derived from EPR is the nitrogen hyperfine splitting constants $\left(\alpha_{N}\right)$, while oxidation potential $\left(E_{\mathrm{ox}}{ }^{0}\right)$ and reversibility are key features of their redox behaviour. Given that nitroxides often must be modified with various functionalities for use in specific applications, ${ }^{25,} 26$ understanding the effects that functional and heteroatom substitutions have on electron spin and, more importantly, redox properties would be of great significance.

Previous theoretical and experimental studies on the impact of chemical structure on the oxidation potentials of different types of nitroxide radicals have generally focussed on changes in ring size and strain. ${ }^{27-31}$ In particular, ring flexibility was found to be an important factor in oxidation and reduction potentials as the cation, anion and radical prefer different degrees of planarity around the nitrogen atom, and attainting the optimal geometric rearrangement is hindered to varying extents by ring rigidity. It has been demonstrated that sterically shielding the radical centre by introducing bulky groups on the carbon atoms adjacent to the nitrogen reduces chain flexibility ${ }^{32}$ and results in a longer radical lifetime. ${ }^{27,28,33,34}$ Modification of the $\alpha$-methyl and/or ortho- or para-substituents has been shown to alter the redox potential through an electronic induction effect. 35,36 Moreover, dipole forces were used by Billone and coworkers to rationalise substituent effects on hydroxylamine bond dissociation enthalpies. ${ }^{37}$ Although these studies have elucidated some of the effects of substitution on the chemistry of nitroxides, there is still a lack of knowledge on the influence of both substituents and heteroatoms on nitroxide oxidation potentials.

In this work, we have synthesized twenty nitroxides, including four new structures $(\mathbf{e}, \mathbf{f}, \mathbf{q}$ and $\mathbf{t}$ ) that have different functional substitutions and/or heteroatom insertions in their cyclic structures (Scheme 1). These compounds allow us to systematically investigate the influence of substitution and heteroatoms on both the oxidation properties and electron spin behaviour. We also carried out complimentary computational studies to provide insight into how substituents can affect these oxidation potentials. In this way, we develop simple predictive relationships between the properties of the substituent and the resulting oxidation potential so that nitroxides can be rationally designed for their desired applications.

Scheme 1. Substituted and heterocyclic nitroxide radicals studied in this work.

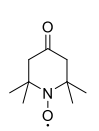

(a)

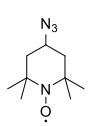

(h)

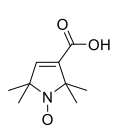

(o)

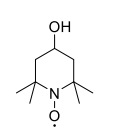

(b)

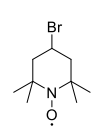

(i)

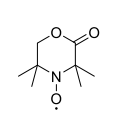

(p)

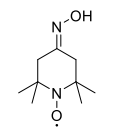

(c)

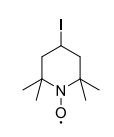

(j)

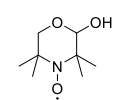

(q)

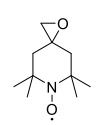

(d)

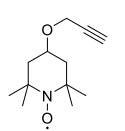

(k)

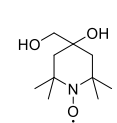

(e)

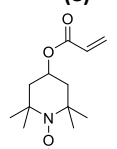

(I)

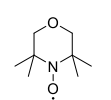

(r)

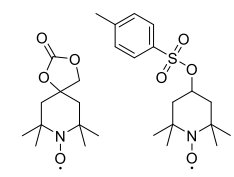

(f)

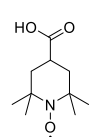

(m)

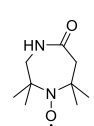

(s) (g)

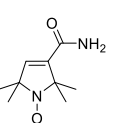

(n)

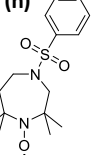

(t) 


\section{Experimental}

\subsection{Synthesis}

Full synthesis and characterisation are provided in the Supporting Information; a brief summary is presented here. The nitroxides synthesized and studied in this work are listed in Scheme 1. Radical $\mathbf{m}$ was purchased from Aldrich and used as received. Synthesis of a-I started from the commercially available triacetoneamine (1) as illustrated in Scheme 2. Radicals $(\mathbf{a}-\mathbf{m})$ are TEMPO derivatives with different functionalities at the 4-position. Both 4-oxo- TEMPO (a) and 4hydroxyl-TEMPO (b) were synthesized according the literature. ${ }^{16}$ Oxidation of (1) by hydrogen peroxide (30 wt \%), sodium tungstate and EDTA, as previously reported, gave (a) with high yield (> 80\%). However, the oxidation process needs to be carried out in a dilute solution ([1] $0.1 \mathrm{M}$ ) with slow addition of hydrogen peroxide under ice water cooling to prevent over-oxidation and consequent decrease in the yield. 4hydroxylamino-TEMPO (c) was synthesized in high yield (75\%) through the reaction of (a) with hydroxylamine hydrochloride under basic conditions. 4-oxiranyl-TEMPO (d) was synthesized from (a) in the presence of sulfur ylide through a one-step Corey-Chaykovsky reaction. ${ }^{38} \mathrm{Hydrolysis}$ of (d) in potassium hydroxide DMSO $/ \mathrm{H}_{2} \mathrm{O}$ solution (15 wt\%) at $60{ }^{\circ} \mathrm{C}$ afforded the dihydroxyl functionised nitroxide (e) in a $45 \%$ yield. Nitroxide (e) was further converted into a spirocyclic carbonate radical (f) through a transesterification with dimethyl carbonate, with an isolated yield of $51 \%$. Nitroxides $\mathbf{d}$ and $\mathbf{f}$ are monomers and could be further polymerized through ring-opening polymerization, resulting in polyether or polycarbonate based nitroxide radical polymers. 4-Tosylate-TEMPO (g), 4-propargylTEMPO (k) and 4-acryloyl-TEMPO (I) were synthesized according to previous reports. ${ }^{39} 4$-Tosylate-TEMPO (g) was used to synthesize 4-azido-TEMPO (h) and 4-iodo-TEMPO (j) through nucleophilic substitution with sodium azide and sodium iodide, respectively. 4-bromo-TEMPO (i) was synthesized through Appel bromination of 4-hydroxyl-TEMPO (b) in the presence of $\mathrm{PPh}_{3} / \mathrm{CBr}_{4}$ and recovered in low yield ( 10\%).
Scheme 2. Synthesis of 4-substituted TEMPO radicals from triacetoneamine (1).

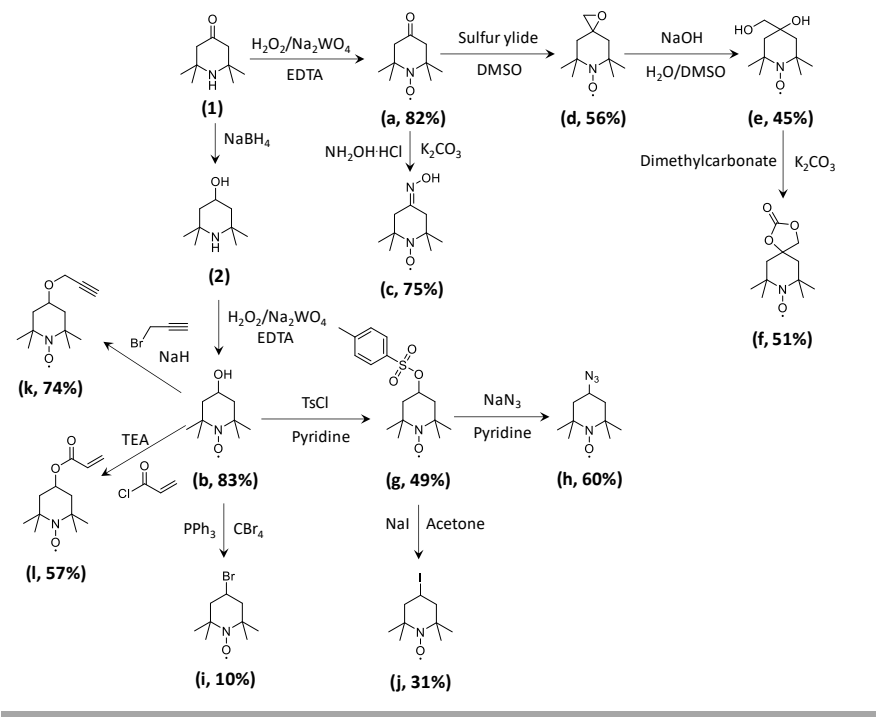

Synthesis of the five-membered cyclic PROXYL radicals $\mathbf{n}$ and $\mathbf{o}$ was achieved through a ring-contraction reaction from triacetoneamine (1), as shown in Scheme 3. 1 was first brominated in acetic acid and gave a mixture of 3,3-dibromo (3a) and 3,5-dibromo (3b) substituted triacetoneamine, which was confirmed by ${ }^{1} \mathrm{H}$ NMR showing two distinct peaks at 5.41 ppm and $4.35 \mathrm{ppm}$ ascribed to the protons adjacent to the ketone (Figure S1). The ratio of $\mathbf{3 a : 3 b}$ was about $1: 3$ and the mixture (3) was converted without further purification to the same product (4) (Figure S2) through a Favorskii rearrangement in $28 \%$ aqueous ammonia with an isolated yield of $75 \%$. Oxidation of (4) afforded nitroxide ( $n$ ) with a yield of $42 \%$. Further hydrolysis of $(\mathbf{n})$ produced the carboxylic acid functionised nitroxide (o) with nearly quantitative yield (95\%). Seven-membered heterocyclic nitroxides ( $\mathbf{s}$ and $\mathbf{t}$ ) were synthesized through a ring-expansion reaction. Triacetoneamine was directly reacted with sodium azide in the presence of concentrate hydrochloric acid (36 wt\%) (Caution: this forms highly toxic $\mathrm{HN}_{3}$, slow addition of $\mathrm{NaN}_{3}$ in a wellvented system is required) and formed a caprolactam with secondary amine (5) through a one-step Schmidt rearrangement with an isolated yield of $53 \%$. Product 5 was first confirmed by NMR (Figure S3), and further oxidised to the caprolactam nitroxide $\mathbf{s}(61 \%)$. Precursor 5 can also be reduced to 6 , in which the less sterically hindered secondary amine was tosylated to give 7 (34\%; Figure S4). Oxidation of 7 produced nitroxide $\mathbf{t}$ with a yield of $67 \%$. 
Scheme 3. Synthesis of 5-membered pyrroline and 7-membered heterocyclic nitroxides through Favorskii ring-contraction and Schmidt ring-expansion reactions, respectively.

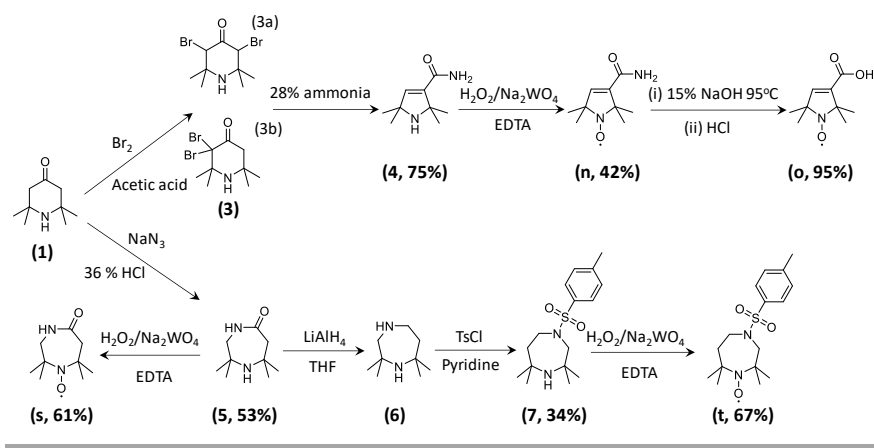

Six-membered heterocyclic nitroxides ( $\mathbf{p}, \mathbf{q}$ and $\mathbf{r}$ ) were synthesized through Lai's ring-closure reaction starting with simple chemicals as illustrated in Scheme 4.40, 41 Precursor 8 (Figure S5) was oxidised to the valerolactone radical $\mathbf{p}$ with a yield of $84 \%$, which can be further reduced to the hemiacetal radical $\mathbf{q}$ by $\mathrm{NaBH}_{4}$. Following successive reduction and ringclosure reactions of $\mathbf{8}$, the morpholine radical $\mathbf{r}$ was obtained after oxidation of $\mathbf{1 0}$ (Figure S6) with a yield of $66 \%$.
Scheme 4. Synthesis of 6-membered heterocyclic nitroxides through ring closure reactions.

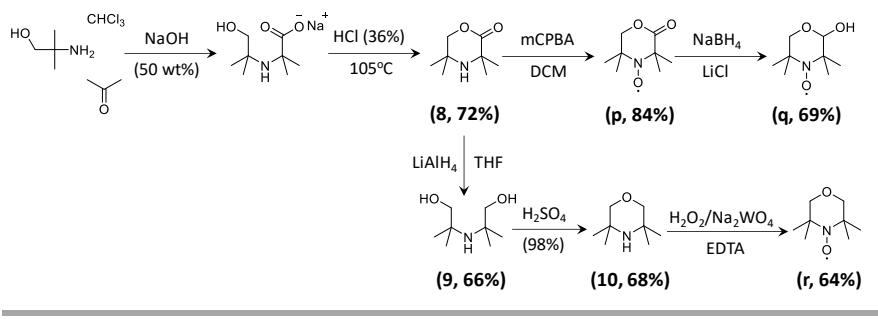

\subsection{Cyclic Voltammetry (CV)}

The cyclic voltammetry (CV) measurements were performed on a potentiostat system (CHI-760D) using a conventional threeelectrode cell at $25^{\circ} \mathrm{C}$. A glass carbon electrode was used as the working electrode and polished with 0.3 and $0.05 \mu \mathrm{m}$ alumina slurry after each measurement. A coiled platinum wire and an $\mathrm{Ag} / \mathrm{AgNO}_{3}$ electrode were used as the counter and the reference electrodes, respectively. The cyclic voltammograms were measured using $5 \mathrm{mM}$ nitroxide solution in $\mathrm{MeCN}$ (with

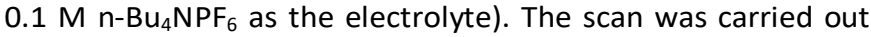
for three cycles with scan rate of $50 \mathrm{mV} / \mathrm{s}$. For all the nitroxides examined, redox waves of the three scans overlapped very well, therefore only one scan was reported. The final reported potentials of all the nitroxides were corrected by using ferrocene $(\mathrm{Fc}) /$ ferrocenium $\left(\mathrm{Fc}^{+}\right)$couple $(5 \mathrm{mM})$ as a reference.

Table 1. Experimental and computational data for substituted and heterocyclic nitroxides. ${ }^{a}$

\begin{tabular}{|c|c|c|c|c|c|c|c|c|c|c|}
\hline \multirow{2}{*}{$\begin{array}{l}\text { Nitroxide } \\
\text { radical }\end{array}$} & $E_{\mathrm{pa}}{ }^{\mathrm{b}}$ & $E_{\mathrm{pc}}^{\mathrm{b}}$ & $E_{\text {ox }}{ }^{0 \mathrm{c}}$ & $\Delta E_{\mathrm{p}}^{\mathrm{d}}$ & \multirow{2}{*}{$i_{\mathrm{pa}} / i_{\mathrm{pc}}$} & \multirow{2}{*}{$\begin{array}{r}E_{\text {Cald. }}^{0} \\
\mathrm{mV})\end{array}$} & \multirow{2}{*}{$\begin{array}{c}\text { Natural Charge } \\
\text { on Oxygen }^{f}\end{array}$} & \multirow{2}{*}{$\begin{array}{l}\text { Dipole moment } \\
\text { (D) }\end{array}$} & \multirow{2}{*}{$\begin{array}{l}\text { Quadrupole moment } \\
\qquad(\mathrm{DA})^{\mathrm{g}}\end{array}$} & \multirow[b]{2}{*}{$\alpha_{N}(G)^{h}$} \\
\hline & \multicolumn{4}{|c|}{$\left(\mathrm{mV}\right.$ vs Fc/Fc $\left.\mathrm{Fc}^{+}\right)$} & & & & & & \\
\hline TEMPO & 298 & 170 & 234 & 128 & 1.00 & - & -0.4331 & -0.1401 & -0.0100 & 15.630 \\
\hline a & 468 & 352 & 410 & 116 & 1.01 & 450 & -0.4262 & 3.3042 & -2.3756 & 14.239 \\
\hline b & 346 & 222 & 284 & 124 & 1.04 & 231 & -0.4295 & 0.2585 & 0.1100 & 15.205 \\
\hline c & 397 & 282 & 340 & 115 & 0.99 & 369 & -0.4301 & 0.6338 & 2.5832 & 14.546 \\
\hline e & 286 & 174 & 230 & 112 & 1.01 & 202 & -0.4293 & -0.2485 & 0.3842 & 15.132 \\
\hline f & 446 & 332 & 389 & 114 & 0.99 & 385 & -0.4206 & 3.288 & -2.1385 & 14.854 \\
\hline g & 448 & 325 & 387 & 123 & 0.99 & 437 & -0.4267 & 4.0126 & -16.2413 & 15.103 \\
\hline $\mathbf{h}$ & 411 & 297 & 354 & 114 & 0.99 & 316 & -0.4258 & 2.1371 & -0.9547 & 15.161 \\
\hline $\mathbf{i}$ & 419 & 325 & 372 & 94 & 0.99 & 385 & -0.4251 & 2.5359 & -1.0463 & 15.088 \\
\hline $\mathbf{j}$ & 400 & 303 & 352 & 97 & 1.00 & & & & & 15.308 \\
\hline $\mathbf{k}$ & 373 & 242 & 308 & 131 & 0.99 & 246 & -0.4300 & 0.2442 & -0.0657 & 15.161 \\
\hline m & 377 & 253 & 315 & 124 & 0.99 & 342 & -0.4278 & 0.9448 & 2.4111 & 15.206 \\
\hline$n$ & 499 & 399 & 449 & 100 & 1.05 & 453 & -0.4195 & -0.1002 & 7.0033 & 14.209 \\
\hline 0 & 542 & 427 & 485 & 115 & 0.98 & 527 & -0.4197 & 0.7268 & 4.4555 & 14.092 \\
\hline $\mathbf{p}$ & 692 & 580 & 636 & 112 & 1.02 & 700 & -0.4157 & 4.6521 & -1.1516 & 13.770 \\
\hline$q$ & 359 & & & & & & & & & 15.030 \\
\hline$r$ & 397 & 318 & 358 & 79 & 0.97 & 343 & -0.4252 & 1.3241 & -0.4108 & 15.073 \\
\hline$s$ & 458 & & & & & & & & & 15.088 \\
\hline$t$ & 339 & & & & & & & & & 14.810 \\
\hline
\end{tabular}

a Experiments were performed using $5 \mathrm{mM}$ solution in $\mathrm{MeCN}\left(0.1 \mathrm{M} \mathrm{NH}_{4} \mathrm{PF}_{6}\right)$ degassed under nitrogen. Glassy Carbon working electrode, Platinum auxiliary electrode and non-aqueous $\mathrm{Ag} / \mathrm{AgNO}_{3}$ reference electrode. Sweep rate is $100 \mathrm{mV} \cdot \mathrm{s}^{-1}$. ${ }^{\mathrm{b}} E_{\mathrm{pa}}$ and $E_{\mathrm{pc}}$ was calibrated versus $\mathrm{Fc} / \mathrm{Fc}^{+} .{ }^{c} E_{\mathrm{ox}}{ }^{0}=\left(E_{\mathrm{pa}}+E_{\mathrm{pc}}\right) / 2 .{ }^{\mathrm{d}} \Delta E_{\mathrm{p}}=E_{\mathrm{pa}}-E_{\mathrm{pc}}$. e $\mathrm{Calculated}$ at the $\mathrm{G} 3(\mathrm{MP2}, \mathrm{CC})(+) / / \mathrm{M06}-2 \mathrm{X} / 6-31+\mathrm{G}(\mathrm{d}, \mathrm{p})$ level of theory in conjunction with PCM solvation corrections, the values were corrected based on TEMPO (i.e. $234 \mathrm{mV}$ ) (see Supporting Information for more details). ${ }^{\mathrm{B}}$ Based on $\mathrm{M} 06-2 \mathrm{X} / 6-31+\mathrm{G}(\mathrm{d}, \mathrm{p})$ calculations (taking a weighted average of nitroxide conformations). $\mathrm{g}$ Based on M06-2X/6$31+G(d, p)$ calculations of the corresponding cyclohexyl derivative (see text, taking a weighted average of nitroxide and oxoammonium conformations). $h$ The nitrogen hyperfine splitting constants $\left(\alpha_{N}\right)$ were measured from ESR spectra. $1 \mathrm{mg} / \mathrm{ml}$ in methanol, X-Band, Attenuation $25 \mathrm{Gd}$. 

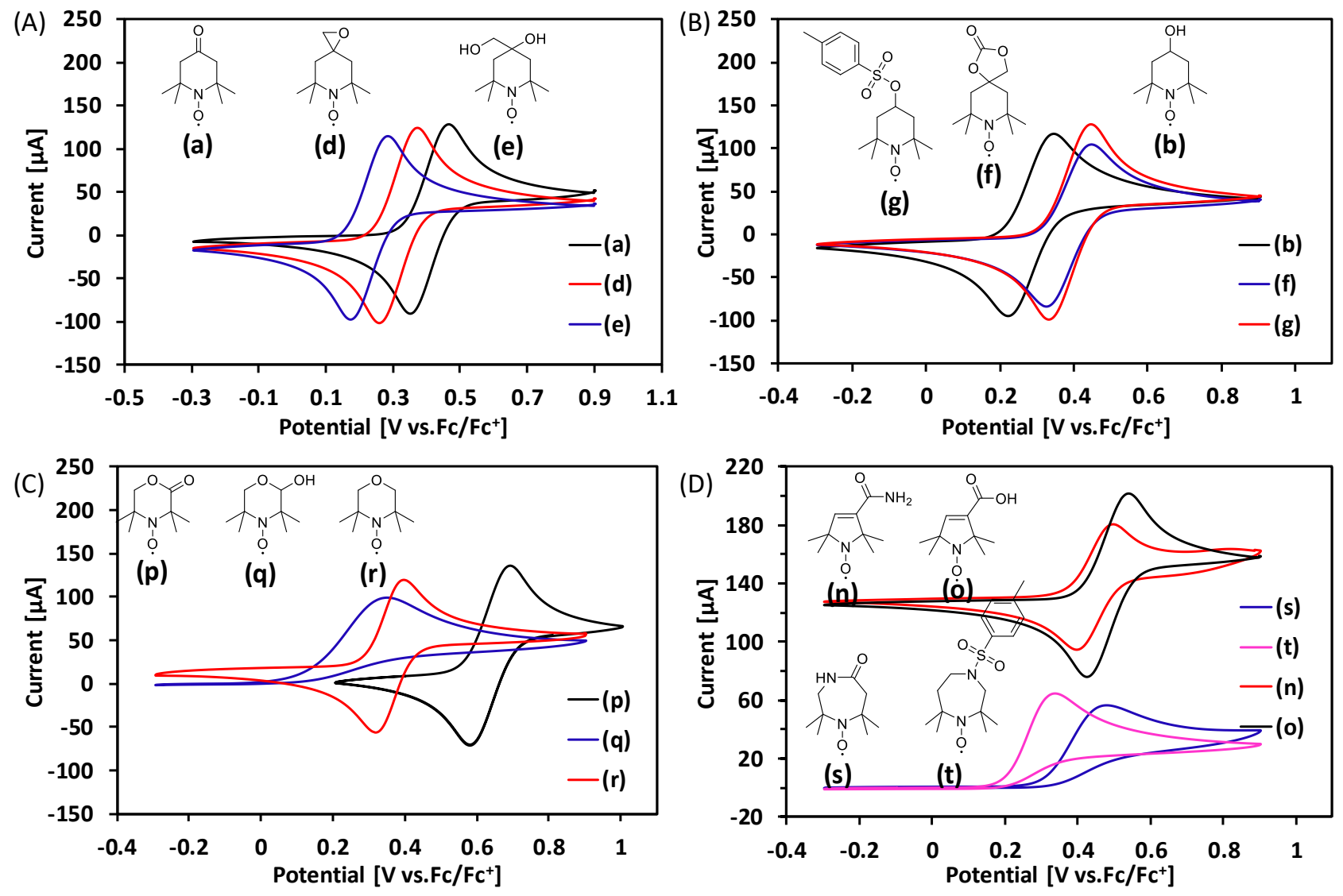

\subsection{Electron Spin Resonance (ESR)}

ESR spectra were recorded with a Bruker E540 spectrometer operating at X-band $(\sim 9.8 \mathrm{GHz})$ and using a Bruker ER4122SQEW1 high sensitivity resonator. Samples were measured at 1.0 $\mathrm{mg} / \mathrm{mL}$ in methanol in a $1.5 \mathrm{~mm}$ internal diameter capillary with the following instrumental parameters, microwave power = $0.635 \mathrm{~mW}$, modulation amplitude $=1 \mathrm{G}$. The spectra were processed using Bruker Xepr software.

\subsection{Theoretical Methodology}

Standard ab initio molecular orbital theory and density functional theory (DFT) calculations were carried out using Gaussian $09^{42}$ with the exception of $\operatorname{CCSD}(T)$ calculations, which were performed using Molpro 2015.43, 44 Calculations were performed at a high level of theory, previously shown to reproduce experimental redox potentials for other nitroxide radicals. ${ }^{45,} 46$ Geometries of all species were optimised at the M06-2X $X^{47}$ level of theory using the $6-31+G(d, p)$ basis set and frequencies, entropies and thermal corrections were also calculated at this level of theory. Improved single-point energies were calculated using the high-level composite ab initio $\mathrm{G} 3(\mathrm{MP} 2, \mathrm{CC})(+)$ method, a variation of standard G3(MP2,CC) 48 where calculations with the 6-31G(d) basis set are replaced with $6-31+G(d)$. These high-level calculations where utilized in conjunction with the ONIOM approximation ${ }^{49}$, 50 for larger systems, with UMP2 used to model remote substituents effects. Solvation corrections were calculated using the polarisable continuum model (PCM) ${ }^{51}$ (as implemented in Gaussian 09). Natural charges were calculated in Gaussian software via its built-in Natural Bond Orbital population analysis ${ }^{52}$ at the M06$2 X / 6-31+G(d, p)$ level. A more detailed description of the computational methodology can be found in the Supporting Information.

\section{Results and discussion}

\subsection{Electrochemical results}

The oxidation potentials of nitroxides play an important role when these compounds are used as alcohol oxidation catalysts, redox mediators for solar cells $s^{31}$ and electroactive materials for organic radical batteries. ${ }^{23}, 35$ In the latter case, a higher oxidation potential means a greater energy storage capacity. We therefore studied the oxidation potentials for all the synthesized nitroxides by cyclic voltammetry (CV) using a threeelectrode system with $\mathrm{Fc} / \mathrm{Fc}^{+}$as the reference (Fc: Ferrocene); the data are listed in Table 1. For previously studied nitroxides, excellent agreement was observed between our oxidation potentials and those in the literature (see Table S1). ${ }^{28,29,53}$ It was found that for all 4-substituted TEMPO derivatives (a-m), the redox reaction had a peak separation $\Delta E_{\mathrm{p}}$ between 94 and $131 \mathrm{mV}$. The cathodic and anodic currents were nearly the same as $i_{\mathrm{pa}} / i_{\mathrm{pc}}$ were very close to 1.0 , suggesting all 4-substituted nitroxides underwent a reversible electrochemical oxidation reaction. The oxidation potentials for $\mathbf{a}-\mathbf{m}$ varied from 230 to 
$410 \mathrm{mV}$ with the highest oxidation potential of $410 \mathrm{mV}$ for 4oxo-TEMPO (a). Modification of 4-oxo-TEMPO (a) to 4-oxiranylTEMPO (d) then to 4-hydroxyl-4'-hydroxymethyl-TEMPO (e) resulted in significant decrease in the oxidation potential from $410 \mathrm{mV}$ to $317 \mathrm{mV}$ then to $230 \mathrm{mV}$ (Figure 1A). Modification of 4-hydroxyl-TEMPO (b) (i.e. $E_{\mathrm{ox}}{ }^{0}=284 \mathrm{mV}$ ) with bulky and electron-withdrawing subsitutents to give 4-spirocarbonateTEMPO (f) or 4-tosyl-TEMPO (g) resulted in an increase in oxidation potentials to 389 and $387 \mathrm{mV}$, respectively (Figure 1B). Other 4-substituted TEMPO derivatives had oxidation potentials around $350 \mathrm{mV}$ as listed in Table 1.

The $\delta$-valerolactone nitroxide $(\mathbf{p})$ possessed the highest oxidation potential of all 20 nitroxides tested, which at $636 \mathrm{mV}$ was around $350 \mathrm{mV}$ higher than the 4-hydroxyl-TEMPO b. In contrast, the morpholine nitroxide $r$ had a potential of $358 \mathrm{mV}$, with only $80 \mathrm{mV}$ higher than $\mathbf{b}$. Reduction of $\mathbf{p}$ by $\mathrm{NaBH}_{4}$ produced hemiacetal nitroxide $\mathbf{q}$ and gave a low anodic potential $E_{\mathrm{pa}}(359 \mathrm{mV})$ and an irreversible peak, which suggests a possible side reaction of the corresponding oxoammonium cation with the hemiacetal group and/or ring-opening and degradation of the radical. This indicates that 6-membered heterocyclic nitroxides have very different oxidation behaviour to 6-membered piperidine radicals (i.e. b). The 5-membered pyrroline nitroxides, $\mathbf{n}$ and $\mathbf{o}$, exhibited oxidation potentials of 449 and $485 \mathrm{mV}$ (vs Fc/Fc'), which were about 100 to $200 \mathrm{mV}$ greater than most of piperidine derivatives. This demonstrates the role of electrostatics (vide infra): the positive quadrupole of the aromatic pyrroline interacts unfavourably with the $>\mathrm{N}^{+}=\mathrm{O}$ cation, making it much harder to oxidise than TEMPO. The heterocyclic caprolactam (s) and 1,4-diazepan (t) nitroxides displayed irreversible oxidation, which suggests that the respective 7-membered cyclic oxoammonium cations were unstable. Comparing $\mathbf{s}$ with $\mathbf{t}$, electronegativity is again responsible for the lowering from $458 \mathrm{mV}$ to $339 \mathrm{mV}$ for nitroxides $\mathbf{s}$ and $\mathbf{t}$, respectively (Figure 1D).

\subsection{Computational results}

Since the oxidation potential of cyclic nitroxides appears to be affected by a combination of electronic inductive effects, steric hindrance and ring size, we first compared the oxidation potentials for only the 4-substituted TEMPO derivatives (a-m), in which only the 4-position was functionalized with different substituents. By using empirical Hammett constants (i.e. $\sigma_{p}$ for para-substitution) taken from the literature, ${ }^{54}$ we examined the correlation between $\sigma_{p}$ and the respective oxidation potential of the nitroxide (see Table 2).

Most of the nitroxides examined displayed a linear relationship between the $\sigma_{p}$ values and their oxidation potential, consistent with the notion that electron-withdrawing groups destabilise the oxoammonium cation resulting in higher oxidation potentials (Scheme 5). This electronic inductive effect can alter the oxidation potential by over $100 \mathrm{mV}$ (Figure 2A). However, nitroxides $\mathbf{d}$, $\mathbf{e}$ and $\mathbf{f}$ were excluded due to their spiroor bis-substitution leading to difficulties in estimating their $\sigma_{p}$ values. An interesting outlier is the carboxylic acid functionalised nitroxide $m$, which largely deviates from the linear trend of mono-substituted nitroxides, possibly because of deprotonation or carboxylic acid dimerisation. SOMO-HOMO conversion of this radical (in its deprotonated form) and associated electrostatic stabilization has been previously reported. ${ }^{55-57}$ When SOMO-HOMO converted, the radical is expected to undergo preferential oxidation at the carboxylate (to form a diradical) rather than the usual oxidation to an oxoammonium cation. Even if the radical is not SOMO-HOMO converted, partial deprotonation or hydrogen bonding (via carboxylic acid dimerisation for instance) would dramatically change the polarity of the substituent.

Table 2. Hammett constants and experimental oxidation potentials for 4subsituted nitroxides.

\begin{tabular}{|c|c|c|c|c|c|c|c|}
\hline & Functional group & $\sigma_{p}{ }^{a}$ & $E_{\text {ox }}{ }^{0}(\mathrm{mV})^{\mathrm{b}}$ & & Functional group & $\sigma_{p}$ & $E_{\mathrm{ox}}{ }^{0}(\mathrm{mV})$ \\
\hline (a) & $=0$ & 0.50 & 410 & (g) & -OTs & 0.33 & 387 \\
\hline (b) & $-\mathrm{OH}$ & -0.37 & 284 & (h) & $-\mathrm{N}_{3}$ & 0.08 & 354 \\
\hline (c) & $=\mathrm{NOH}$ & 0.1 & 340 & (i) & $-\mathrm{Br}$ & 0.23 & 372 \\
\hline (d) & $-\mathrm{CH}_{2} \mathrm{OCH}_{2}-$ & - & 317 & (j) & -1 & 0.18 & 352 \\
\hline (e) & $-\mathrm{CH}_{2} \mathrm{OH} /-\mathrm{OH}$ & - & 230 & (k) & $-\mathrm{OCH}_{2} \mathrm{C} \equiv \mathrm{CH}$ & -0.25 & 343 \\
\hline$(f)$ & Carbonate & - & 389 & (I) & $-\mathrm{OCOCH}=\mathrm{CH}_{2}$ & 0.05 & 308 \\
\hline
\end{tabular}

a Hammett constants were adopted from a previous report, values for $\mathbf{d}$, e and $\mathbf{f}$ were not found, ${ }^{54} \sigma_{p}$ values for $\mathbf{k}$ and I were estimated from the analogue structures $-\mathrm{OCH}_{2} \mathrm{CH}=\mathrm{CH}_{2}$ and $-\mathrm{OCOPh}$, respectively. ${ }^{\mathrm{b}} E_{\mathrm{ox}}{ }^{0}=\left(E_{\mathrm{pa}}+E_{\mathrm{pc}}\right) / 2, E_{\mathrm{pa}}$ and $E_{\mathrm{pc}}$ was calibrated versus $\mathrm{Fc} / \mathrm{Fc}^{+}$.
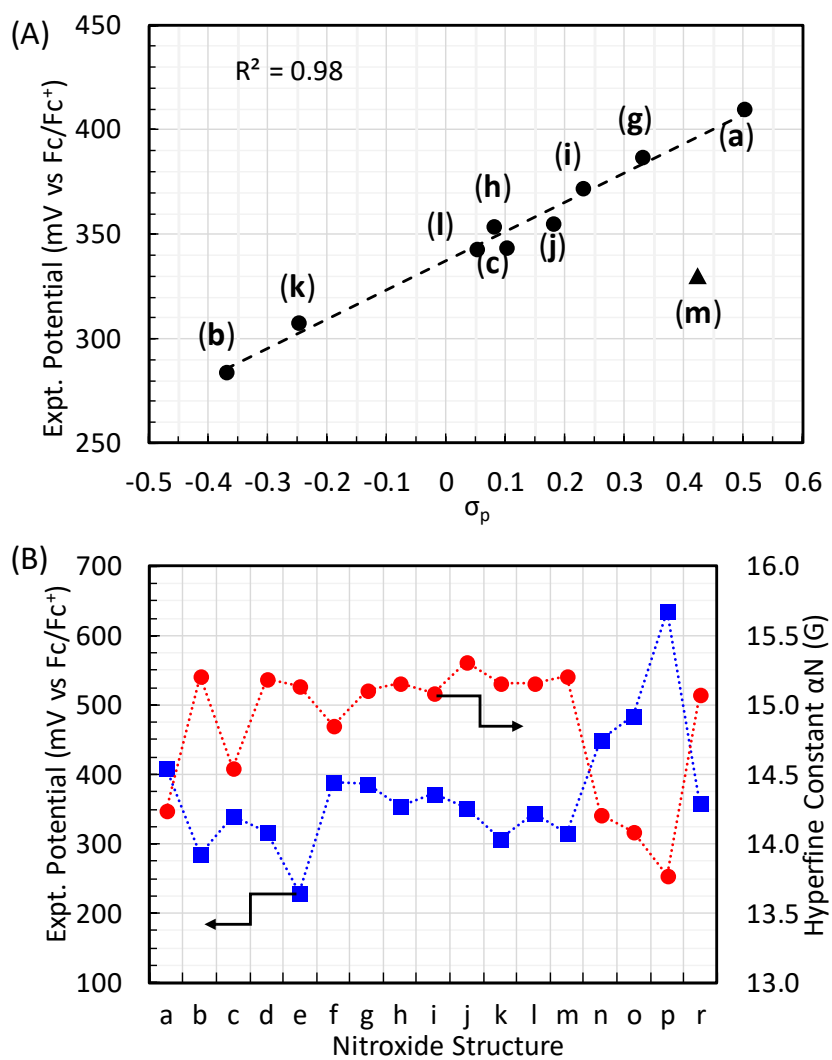

Figure 2. (A) Correlation of experimental oxidation potentials with the Hammett constants $\left(\sigma_{p}\right)$ of 4-substituted nitroxides ( $m$ was excluded from this regression) and (B) Experimental oxidation potentials vs the nitrogen hyperfine splitting constants $\alpha_{\mathrm{N}}$. 
The chemical structure of nitroxide radicals influences not only their oxidation potentials but the values of their nitrogen hyperfine splitting constants $\left(\alpha_{N}\right)$. Hyperfine splitting constants have been utilised to probe solvent polarity, oxygen concentration and redox reactions in biological systems. ${ }^{58,} 59$ Previous work has demonstrated the impact of the ring size, structural conformations, and inductive effects of the substituents of cyclic nitroxide on their $\alpha_{N}$ values, ${ }^{60}$ and some of our results agree well with previous reports. ${ }^{37}$ Generally speaking, the more rigid the ring and the more electronwithdrawing the substituent, the lower the $\pi$-electron spin density is on nitrogen (Scheme 5); hence, $\alpha_{N}$ decreases. In this context, we plotted the experimental oxidation potential $E_{\mathrm{ox}}{ }^{0}$ versus the nitrogen hyperfine splitting constants $\left(\alpha_{N}\right)$ for the nitroxide radicals (Figure $2 \mathrm{~B}$ ). Species $\mathbf{q}, \mathbf{s}$ and $\mathbf{t}$ were omitted because they showed irreversible oxidation. Figure 2B clearly shows that nitroxides with low $\alpha_{N}$ values tend to have correspondingly high oxidation potentials $E_{\mathrm{ox}}{ }^{0}$. Clearly the ability of the nitroxide substituents to delocalise the radical is a good predictor of their ability to stabilize the oxidised oxoammonium cation (i.e. $>\mathrm{N}^{+}=\mathrm{O}$ ).

Scheme 5. Reversible oxidation reaction and resonance delocalization of nitroxide radical.

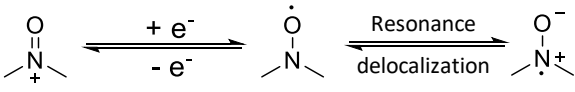

$$
\begin{aligned}
& \left(E_{\text {ox }}{ }^{0}\right) \quad \text { nitroxide radical }\left(\alpha_{N}\right)
\end{aligned}
$$

Next, we examined the agreement between theory and experiment for the oxidation potentials of these nitroxides. Theoretical calculations, carried out at the G3(MP2,CC)(+)//M06-2X/6-31+G(d,p) level of theory with PCM solvation corrections, were shown to reproduce experiment to within a mean absolute deviation of $33 \mathrm{mV}$ and maximum deviation of $64 \mathrm{mV}$ (Figure S7). We also observed reasonable correlation between the natural charge calculated on the nitroxide $O$ atom (calculated at M06-2X/6-31+G(d,p)) and the experimental oxidation potential (Figure $\mathrm{S} 8$ ). This indicates that remote substituents directly affected the electron distribution along the $\mathrm{N}-\mathrm{O}$ bond of the formed oxoammonium cation (Scheme 5) and that these changes correlate with the oxidation potential of these nitroxides.

To ascertain the relationship between the nitroxide structure and its oxidation potential, we considered the underlying electrostatic interactions present in these systems. Non-conjugated substituents affect the oxidation potential by interacting electrostatically with both the polarized bond present in the parent nitroxide (i.e. $>\mathrm{N}^{+\bullet-} \mathrm{O}^{-}$) and the formal charge formed upon its oxidation (i.e. $>\mathrm{N}^{+}=0$ ). 55 , 56 This electrostatic interaction can be written as a multipole expansion in terms of the charge, dipole, quadrupole, etc of the substituent. As all the substituents are formally uncharged, the dipole term is the first non-zero term in the multipole expansion. Provided that the charge-dipole interaction is dominant, alignment of the substituent dipole with the charge should stabilize the oxoammonium cation and result in a lower oxidation potential (Scheme 6). Conversely, misalignment of substituent dipole would destabilize this cation and so raise the oxidation potential. Thus, the orientation and magnitude of the substituent dipole should influence the electrostatic stabilization/destabilization of the oxoammonium cation and in turn effect the oxidation potential of the parent nitroxide.

To assess if the substituent dipole was correlated with the oxidation potential, we calculated the dipole moment using M06-2X/6-31+G(d,p) for various structural analogues of the nitroxides in the test set. To decouple the dipole moment of the substituent from that of the $>\mathrm{N}-\mathrm{O}^{\bullet}$ group, we considered simplified models in which the $>\mathrm{N}-\mathrm{O}^{\bullet}$ moiety was replaced with a $\mathrm{CH}_{2}$ group. This substituent orientation relative to the $>\mathrm{N}-\mathrm{O} \bullet$ moiety is crucial, as this axis defines the only spatial component of the dipole moment that will have a non-zero interaction with the charge formed upon oxidation. As the basic C-C framework of these models is analogous to that of the corresponding nitroxides, the relatively fixed orientations of the interacting substituents are preserved. As shown in Figure S9, the distance scaled dipole moment is very well correlated with the experimental oxidation potentials $\left(R^{2}=0.89\right)$, however nitroxides $\mathbf{g}, \mathbf{n}$ and $\mathbf{o}$ were found to be significant outliers.

Scheme 6. Oxidation of nitroxide radical with differing remote (non-conjugated) substituent dipole orientations.
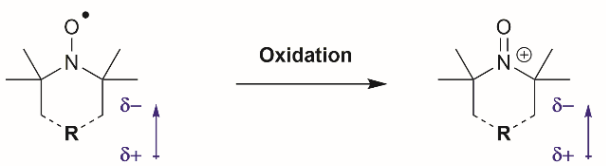

Favourable charge-dipole interaction with
$\mathrm{R}$ substituent

Higher oxidation potential
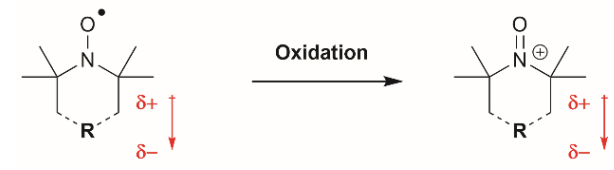

While truncating the multipole expansion at the dipole term is valid if the substituent and $>\mathrm{N}^{+}=\mathrm{O}$ moiety are appreciably separated, at short-range higher order multipole terms may be significant. In particular, the importance of quadrupole moments in the electrostatic description of molecules with $\pi$ systems is well known. ${ }^{61}$ For such systems, analysis based on the dipole moment alone would clearly be inadequate. The residual deviation between the experimental oxidation potential and that predicted by the scaled dipole term is very well correlated with the distance scaled quadrupole moment. For instance, nitroxide $\mathbf{g}$ has a significant stabilizing quadrupole term that arises from the aromatic $\pi$-system of the tosylate group, which explains why truncating multipole analysis at the dipole term leads to a significant overestimation of its oxidation potential. Conversely, nitroxides $\mathbf{n}$ and $\mathbf{o}$ have large destabilizing quadrupole terms that result from the $\mathrm{C}=\mathrm{C}$ bond of the 3 pyrroline rings, which accounts for the significant 
underestimation of their oxidation potentials using dipole analysis.

The inclusion of an appropriately scaled quadrupole term corrects the 3 previous outliers (nitroxides $\mathbf{g}, \mathbf{n}$ and $\mathbf{o}$ ) and simultaneously improves the correlation with the experimental oxidation potential for the other 14 nitroxides. However, to demonstrate the robustness of this analysis, we calculated dipole and quadrupole terms for an addition 18 nitroxides using oxidation potentials taken from References, ${ }^{28}, 29,53$ and converted to $\mathrm{Fc} / \mathrm{Fc}^{+}$using data given in Reference. ${ }^{62}$ These additional nitroxides included a pyrrolidine, 3 azaphenalenes, 11 isoindolines, 2 piperidines and an azepine. Despite the structural diversity of these nitroxides, good correlation was observed between the distance scaled dipole and quadrupole term and the respective oxidation potential (total $R^{2}=0.84$ ). Reassuringly, the optimal ratio between the dipole and quadrupole terms found via a 2-variable regression (1.78:1) is reasonably similar to the theoretical ratio predicted in a multipole expansion (2:1).

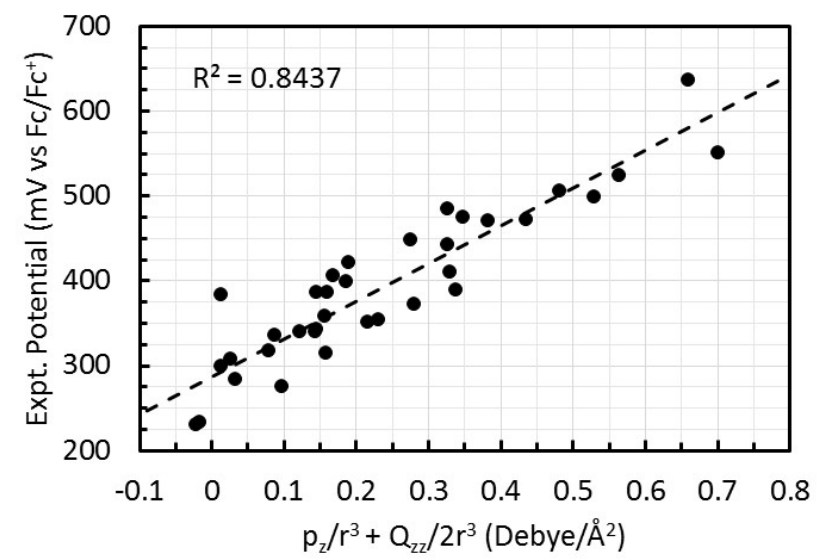

Figure 3. The correlation between the sums of the distance scaled dipole and quadrupole moment of the substituent and the experimental oxidation potential for the 35 nitroxides examined.

The importance of electrostatic effects is nicely illustrated by the 3-carboxy pyrrolidine and pyrroline nitroxides (see Scheme 7.). Interestingly, both species have roughly comparable substituent dipoles, with the saturated pyrrolidine having a less favourable dipole interaction (1.02 D) than the unsaturated pyrroline $(0.73 \mathrm{D})$. Based on their respective substituent dipoles, one might expect that the pyrrolidine nitroxide would have a marginally higher oxidation potential than the pyrroline nitroxide. However, the unsaturated pyrroline has a large destabilizing quadrupole contribution (4.46 DÅ), while the quadrupole contribution for the saturated pyrrolidine is much smaller (0.92 DÅ). By accounting for both terms, the respective oxidation potentials for these two nitroxides can be rationalised.

We should caution that due to relatively small separation between the nitroxide moiety and the substituent, higher order multipole moments may also contribute; particularly in more electrostatically complex systems. Indeed, we note that considering only nitroxides with unsaturated backbones (pyrrolidine, morpholine and piperidine nitroxides) leads to marginally better correlation than is observed for the full test set $\left(R^{2}=0.89\right.$ and $R^{2}=0.84$, respectively). This could point to the importance of higher order multipole descriptors, particularly for nitroxides with unsaturated backbones (e.g. pyrrolines, azaphenalenes, isoindolines and azepines). However, it is important to note that this analysis only considers the underlying (gas-phase) electrostatic effects and does not account for other key factors including; induction, ring reflexibility, through space orbital overlap and explicit solvent effects. Noting that reasonable correlation was observed in Figure 3, we limited our analysis to the more chemically intuitive dipole and quadrupole terms for simplicity.

Scheme 7. A comparison of the experimental oxidation potentials for 3-carboxy pyrrolidine and pyrroline nitroxides as well as their respective substituent dipole and quadrupole moments.<smiles>CC1(C)CC(C(=O)O)C(C)(C)N1[O]</smiles>

3-carboxy pyrrolidine

$$
\begin{aligned}
\mathrm{E}_{\mathrm{ox}}{ }^{0} & =352 \mathrm{mV} \\
\mathrm{p}_{\mathrm{z}} & =0.95 \mathrm{D} \\
\mathrm{Q}_{\mathrm{zz}} & =0.90 \mathrm{DA}
\end{aligned}
$$<smiles>CC1(C)C=C(C(=O)O)C(C)(C)N1[O]</smiles>

3-carboxy pyrroline (nitroxide o)

$$
\begin{aligned}
\mathrm{E}_{\mathrm{ox}}{ }^{0} & =485 \mathrm{mV} \\
\mathrm{p}_{\mathrm{z}} & =0.73 \mathrm{D}
\end{aligned}
$$$$
\mathrm{Q}_{\mathrm{zz}}=4.46 \mathrm{DA}
$$

This analysis clearly demonstrates that the electrostatic properties of the substituent are very closely correlated to the oxidation potential of the corresponding nitroxide. Thus, specific nitroxide oxidation potentials can be targeted by considering the dipole and quadrupole moment of the substituent and its orientation with respect to the $\mathrm{N}-\mathrm{O}$ moiety.

\section{Conclusions}

Theory and experiment have been used to study the effect of substituents on the redox behaviour of nitroxide radicals. The oxidation potential varies over $400 \mathrm{mV}$ with nitroxide ring size and substitution, highlighting their versatility. We have shown that this considerable variation can be explained by the ability of the various substituents to electrostatically stabilize the oxidised form. This stabilisation can be quantified by a simple predictive relationship involving the distance scaled dipole and quadrupole moments of the analogous cyclohexane or cyclopentene ring. This work highlights the often-overlooked role of through-space electrostatic substituent effects, even in formally neutral compounds. Moreover, it provides a simple tool for tuning the oxidation behaviour of nitroxide radicals for use in electrochemical catalysis and energy storage applications.

\section{Conflicts of interest}

There are no conflicts to declare. 


\section{Acknowledgements}

Z.J thanks the financial support from the ARC Future Fellowship and the award of Foundation Research Excellent Award (FREA) from the University of Queensland. M.J.M acknowledges financial support from the ARC Discovery grant. This work was performed in part at the Queensland node of the Australian National Fabrication Facility, a company established under the National Collaborative Research Infrastructure Strategy to provide nano and microfabrication facilities for Australia's researchers. M.L.C acknowledges financial support from ARC Centre of Excellence for Electromaterials Science and generous allocations on the National Facility of the Australian National Computational Infrastructure.

\section{References}

1 N. B. Yapici, S. Jockusch, A. Moscatelli, S. R. Mandalapu, Y. Itagaki, D. K. Bates, S. Wiseman, K. M. Gibson, N. J. Turro and L. R. Bi, Org. Lett., 2012, 14, 50-53.

2 V. Meyer, M. A. Swanson, L. J. Clouston, P. J. Boratynski, R. A. Stein, H. S. Mchaourab, A. Rajca, S. S. Eaton and G. R. Eaton, Biophys. J., 2015, 108, 1213-1219.

3 T. Offer, A. Russo and A. Samuni, FASEB J., 2000, 14, 12151223.

4 B. P. Soule, F. Hyodo, K. Matsumoto, N. L. Simone, J. A. Cook, M. C. Krishna and J. B. Mitchell, Free Radical Bio. Med., 2007, 42, 1632-1650

5 C. Abe, Y. Uto, A. Kawasaki, C. Noguchi, R. Tanaka, T. Yoshitomi, Y. Nagasaki, Y. Endo and H. Hori, J. Control Release, 2014, 182, 67-72.

6 M. Saita, J. Kaneko, T. Sato, S. S. Takahashi, S. WadaTakahashi, R. Kawamata, T. Sakurai, M. C. I. Lee, N. Hamada, K. Kimoto and Y. Nagasaki, Biomaterials, 2016, 76, 292-301.

7 G. Gryn'ova, K. U. Ingold and M. L. Coote, J. Am. Chem. Soc., 2012, 134, 12979-12988.

8 C. J. Hawker, A. W. Bosman and E. Harth, Chem. Rev., 2001, 101, 3661-3688.

9 Z. F. Jia, Q. Fu and J. L. Huang, Macromolecules, 2006, 39, 5190-5193.

10 E. G. Rozantsev, Free Nitroxide Radicals, Springer, New York, 1970.

11 J. B. Gerken and S. S. Stahl, ACS Cent. Sci., 2015, 1, 234-243.

12 A. Badalyan and S. S. Stahl, Nature, 2016, 535, 406-410.

13 M. Rafiee, K. C. Miles and S. S. Stahl, J. Am. Chem. Soc., 2015, 137, 14751-14757.

14 Q. Cao, L. M. Dornan, L. Rogan, N. L. Hughes and M. J. Muldoon, Chem. Commun., 2014, 50, 4524-4543.

15 M. A. Zhang, C. C. Chen, W. H. Ma and J. C. Zhao, Angew. Chem. Int. Ed., 2008, 47, 9730-9733.

16 J. Kulis, C. A. Bell, A. S. Micallef, Z. Jia and M. J. Monteiro, Macromolecules, 2009, 42, 8218-8227.

17 Z. F. Jia, C. A. Bell and M. J. Monteiro, Macromolecules, 2011, 44, 1747-1751.

18 Z. F. Jia, C. A. Bell and M. J. Monteiro, Chem. Commun., 2011, 47, 4165-4167.

19 Q. Fu, W. Lin and J. Huang, Macromolecules, 2008, 41, 23812387.

20 T. Janoschka, N. Martin, U. Martin, C. Friebe, S. Morgenstern, H. Hiller, M. D. Hager and U. S. Schubert, Nature, 2015, 527, 78-81.

$21 \mathrm{H}$. Nishide and K. Oyaizu, Science, 2008, 319, 737-738.

22 T. Suga, H. Ohshiro, S. Sugita, K. Oyaizu and H. Nishide, Adv. Mater., 2009, 21, 1627-1631.

23 T. Janoschka, M. D. Hager and U. S. Schubert, Adv. Mater., 2012, 24, 6397-6409.
24 K. Zhang, Y. Hu, L. Wang, J. Fan, M. J. Monteiro and Z. Jia, Polym. Chem., 2017, 8, 1815-1823.

25 K. Zhang, M. J. Monteiro and Z. Jia, Polym. Chem., 2016, 7, 5589-5614.

26 T. Yamasaki, Y. Ito, F. Mito, K. Kitagawa, Y. Matsuoka, M. Yamato and K. Yamada, J. Org. Chem., 2011, 76, 4144-4148.

27 J. L. Hodgson, M. Namazian, S. E. Bottle and M. L. Coote, J. Phys. Chem. A, 2007, 111, 13595-13605.

28 J. P. Blinco, J. L. Hodgson, B. J. Morrow, J. R. Walker, G. D. Will, M. L. Coote and S. E. Bottle, J. Org. Chem., 2008, 73, 67636771.

29 S. D. Rychnovsky, R. Vaidyanathan, T. Beauchamp, R. Lin and P. J. Farmer, J. Org. Chem., 1999, 64, 6745-6749.

30 M. Kavala, R. Boca, L. Dlhan, V. Brezova, M. Breza, J. Kozisek, M. Fronc, P. Herich, L. Svorc and P. Szolcsanyi, J. Org. Chem., 2013, 78, 6558-6569.

31 G. Gryn'ova, J. M. Barakat, J. P. Blinco, S. E. Bottle and M. L. Coote, Chemistry, 2012, 18, 7582-7593.

32 I. A. Kirilyuk, A. A. Bobko, S. V. Semenov, D. A. Komarov, I. G. Irtegova, I. A. Grigor'ev and E. Bagryanskaya, J. Org. Chem., 2015, 80, 9118-9125.

33 I. A. Kirilyuk, Y. F. Polienko, O. A. Krumkacheva, R. K. Strizhakov, Y. V. Gatilov, I. A. Grigor'ev and E. G. Bagryanskaya, J. Org. Chem., 2012, 77, 8016-8027.

34 Y. Wang, J. T. Paletta, K. Berg, E. Reinhart, S. Rajca and A. Rajca, Org. Lett., 2014, 16, 5298-5300.

35 D. P. Hickey, D. A. Schiedler, I. Matanovic, P. V. Doan, P. Atanassov, S. D. Minteer and M. S. Sigman, J. Am. Chem. Soc., 2015, 137, 16179-16186.

36 T. Yamasaki, F. Mito, Y. Ito, S. Pandian, Y. Kinoshita, K. Nakano, R. Murugesan, K. Sakai, H. Utsumi and K. Yamada, J. Org. Chem., 2011, 76, 435-440.

37 P. S. Billone, P. A. Johnson, S. Lin, J. C. Scaiano, G. A. DiLabio and K. U. Ingold, J. Org. Chem., 2011, 76, 631-636.

38 V. K. Aggarwal and C. L. Winn, Acc. Chem. Res., 2004, 37, 611620.

39 Z. F. Jia, D. E. Lonsdale, J. Kulis and M. J. Monteiro, ACS Macro Lett., 2012, 1, 780-783.

40 A. McNally, B. Haffemayer, B. S. L. Collins and M. J. Gaunt, Nature, 2014, 510, 129-133.

41 S. D. Rychnovsky, T. Beauchamp, R. Vaidyanathan and T. Kwan, J. Org. Chem., 1998, 63, 6363-6374.

42 J. Frisch, G. W. Trucks, H. B. S. Schlegel, G. E., M. A. Robb, J. R. Cheeseman, G. Scalmani, V. Barone, B. Mennucci, G. A. Petersson, H. Nakatsuji, M. Caricato, X. Li, H. P. Hratchian, A. F. Izmaylov, J. Bloino, G. Zheng, J. L. Sonnenberg, M. Hada, M. Ehara, K. Toyota, R. Fukuda, J. Hasegawa, M. Ishida, T. Nakajima, Y. Honda, O. Kitao, H. Nakai, T. Vreven, J. A. Montgomery, J. Peralta, J. E., F. Ogliaro, M. Bearpark, J. J. Heyd, E. Brothers, K. N. Kudin, V. N. Staroverov, T. Keith, R. Kobayashi, J. Normand, K. Raghavachari, A. Rendell, J. C. Burant, S. S. Iyengar, J. Tomasi, M. Cossi, N. Rega, J. M. Millam, M. Klene, J. E. Knox, J. B. Cross, V. Bakken, C. Adamo, J. Jaramillo, R. Gomperts, R. E. Stratmann, O. Yazyev, A. J. Austin, R. Cammi, C. Pomelli, J. W. Ochterski, R. L. Martin, K. Morokuma, V. G. Zakrzewski, G. A. Voth, P. Salvador, J. J. Dannenberg, S. Dapprich, A. D. Daniels, O. Farkas, J. B. Foresman, J. V. Ortiz, J. Cioslowski and D. J. Fox, Gaussian, Inc., Wallingford CT, 2013.

43 H.-J. Werner, P. J. Knowles, G. Knizia, F. R. Manby and M. Schütz, Wiley Interdisciplinary Reviews: Computational Molecular Science, 2012, 2, 242-253.

44 H.-J. Werner, P. J. Knowles, G. Knizia, F. R. Manby, M. Schütz, P. G. Celani, W. , D. K. Kats, T. , R. Lindh, A. Mitrushenkov, G. S. Rauhut, K. R. , T. B. A. Adler, R. D. , A. Bernhardsson, A. C. Berning, D. L. , M. J. O. Deegan, A. J. Dobbyn, F. Eckert, E. Goll, C. Hampel, A. Hesselmann, G. Hetzer, T. Hrenar, G. Jansen, C. Köppl, Y. Liu, A. W. Lloyd, R. A. Mata, A. J. May, S. J. 
McNicholas, W. Meyer, M. E. Mura, A. Nicklass, D. P. O'Neill, P. Palmieri, D. Peng, K. Pflüger, R. Pitzer, M. Reiher, T. Shiozaki, H. Stoll, A. J. Stone, R. Tarroni, T. Thorsteinsson and M. Wang, 2015.

45 G. Gryn'ova, J. M. Barakat, J. P. Blinco, S. E. Bottle and M. L. Coote, Chem Eur. J., 2012, 18, 7582-7593.

46 L. Zhang, Y. B. Vogel, B. B. Noble, V. R. Gonçales, N. Darwish, A. L. Brun, J. J. Gooding, G. G. Wallace, M. L. Coote and S. Ciampi, J. Am. Chem. Soc., 2016, 138, 9611-9619.

47 Y. Zhao and D. G. Truhlar, Theor. Chem. Acc., 2008, 120, 215 241.

48 L. A. Curtiss, K. Raghavachari, P. C. Redfern, A. G. Baboul and J. A. Pople, Chem. Phys. Lett., 1999, 314, 101-107.

49 E. I. Izgorodina, D. R. B. Brittain, J. L. Hodgson, E. H. Krenske, C. Y. Lin, M. Namazian and M. L. Coote, J. Phys. Chem. A, 2007 111, 10754-10768.

$50 \mathrm{M}$. L. Coote, E. H. Krenske and E. I. Izgorodina, Macromolecular Rapid Commun., 2006, 27, 473-497.

51 J. Tomasi, B. Mennucci and R. Cammi, Chem. Rev., 2005, 105, 2999-3094.

52 J. P. Foster and F. Weinhold, J. Am. Chem. Soc., 1980, 102, 7211-7218.

53 M. B. Lauber and S. S. Stahl, ACS Cat., 2013, 3, 2612-2616.

54 C. Hansch, A. Leo and R. W. Taft, Chem. Rev., 1991, 91, 165195.

55 G. Gryn'ova, D. L. Marshall, S. J. Blanksby and M. L. Coote, Nat. Chem., 2013, 5, 474-481.

56 G. Gryn'ova and M. L. Coote, J. Am. Chem. Soc., 2013, 135, 15392-15403.

57 M. Klinska, L. M. Smith, G. Gryn'ova, M. G. Banwell and M. L. Coote, Chem. Sci., 2015, 6, 5623-5627.

58 B. R. Knauer and J. J. Napier, J. Am. Chem. Soc., 1976, 98, 43954400.

59 J. Shen, S. Bottle, N. Khan, O. Grinberg, D. Reid, A. Micallef and H. Swartz, Appl. Magn. Reson., 2002, 22, 357-368.

60 M. F. Ottaviani, G. Martini and L. Nuti, Magn. Reson. Chem., 1987, 25, 897-904.

61 A. S. Mahadevi and G. N. Sastry, Chem. Rev., 2013, 113, 21002138.

62 V. V. Pavlishchuk and A. W. Addison, Inorganica Chimica Acta, 2000, 298, 97-102. 